\title{
A longitudinal and case-control study of dropout among drug users in methadone maintenance treatment in Haiphong, Vietnam
}

Pham Minh Khue ${ }^{1 \dagger}$, Nguyen Thi Tham ${ }^{1 \dagger}$, Dinh Thi Thanh Mai ${ }^{1}$, Pham Van Thuc ${ }^{1}$, Vu Minh Thuc ${ }^{1,2^{*}}$, Pham Van $\operatorname{Han}^{1}$ and Christina Lindan ${ }^{3+}$

\begin{abstract}
Background: Vietnam began providing methadone maintenance therapy (MMT) in 2008; as of June 2016, 44,479 persons who inject drugs (PWID) were in treatment in 57 provinces. However, 10-23\% of patients were estimated to have dropped out of treatment during the first 2 years. We evaluated dropout and factors associated with quitting treatment.
\end{abstract}

Methods: We followed clients $\geq 18$ years old enrolled in five MMT clinics in Haiphong for 3 years. Persons who missed a consecutive month of methadone treatment were considered to have dropped out and were not allowed to return; those who missed greater than five consecutive doses were considered to be non-compliant but were allowed to restart treatment at their initial dose. Clients who dropped out or who were non-compliant during their third year of MMT (cases) were traced and matched with two clients who remained in treatment (controls) by gender, age, and length of time in the program. Cases and controls were interviewed. Additional data on levels of yearly retention were abstracted from clinic records.

Results: Among the 1055 patients initially enrolled in MMT, dropout and non-compliance combined was 13.6\% during the first year, 16.5\% during the second year, and 22.3\% during the third year. By 36 months, 33.3\% of clients had dropped out, of whom $10.6 \%$ had died and $24 \%$ had been arrested. We traced and interviewed 81 clients who dropped out or who were non-compliant during year 3 as well as 161 controls. The primary reasons for dropping out included claiming no dependence on heroin (22.2\%), conflict with work (21.0\%), health problems (16.0\%), and inability to afford the methadone co-payment of approximately $0.5 \mathrm{USD} /$ day (14.8\%). Independent factors associated with non-compliance included continuing to use heroin ( $\mathrm{aOR}=12.4,95 \% \mathrm{Cl} 4.2-36.8)$ and missing greater than three doses during the previous 3 months ( $\mathrm{aOR}=18.5,95 \% \mathrm{Cl} 7.4-47.1)$; receiving a daily dose of $>120 \mathrm{mg}$ of methadone was associated with a lower odds ratio of dropping out ( $\mathrm{aOR}=0.3,95 \% \mathrm{Cl} 0.1-0.9)$.

Conclusion: By 3 years, one third of all patients in treatment had permanently dropped out. Ensuring that methadone dosing is adequate and reducing or eliminating the co-payment fee for those who cannot afford it could improve retention.

Keywords: Drug use, Methadone maintenance treatment, Opioid substitution, Dropout, Vietnam, HIV

\footnotetext{
* Correspondence: vuminhthuc2001@gmail.com

${ }^{\dagger}$ Equal contributors

'Haiphong University of Medicine and Pharmacy, 72A, Nguyen Binh Khiem,

Ngo Quyen, Haiphong, Vietnam

${ }^{2}$ The State Council for Professor Title of Vietnam, 1, Dai Co Viet, Bach Khoa,

Hai Ba Trung, Hanoi, Vietnam

Full list of author information is available at the end of the article
} 


\section{Background}

People who inject drugs (PWID) account for more than half of all people infected with HIV in Vietnam $[1,2]$. The HIV prevalence among those who inject drugs is estimated to be $33 \%$ and ranges from 3 to $58 \%$ in different provinces [3]. Methadone maintenance therapy (MMT) became available in Vietnam in 2008, with the first pilot clinics opening in Haiphong and Ho Chi Minh City [4]. MMT has been shown to reduce transmission of HIV and other blood-borne infections, improve the health and quality of life of those addicted to opiates, and support reintegration into the community [5-8].

The total number of PWID in Vietnam is estimated to be around 260,000, about 10,000 of whom reside in Haiphong, the third largest city in the country [9]. Between 2008 and 2010, more than 2500 PWID in Haiphong were enrolled in the three available MMT clinics [10]; in 2011, five new clinics were opened, and since then, 1055 additional clients have started treatment [11]. Pregnant women, persons who are HIV infected, and those who have families that support their enrolment are given preference to enroll in MMT programs $[4,12]$. Haiphong is divided into 14 districts, and patients can only receive methadone in the district in which they or their family are registered. Clients are required to attend the clinic daily to receive their dose. After 1 year of treatment, patients can start reducing their dose in an effort to discontinue methadone, but most continue on maintenance therapy [12].

Initial data from the MMT pilot program in Haiphong and Ho Chi Minh City showed a promising impact of methadone on individual patients' lives [7], and the government hoped that greater availability of treatment could help limit HIV transmission in the country as a whole [13]. In June 2013, 61 methadone clinics were providing treatment to nearly 14,000 drug users; the Ministry of Health set a target of treating 80,000 drug users by 2015 [4]. To help finance this expansion, clients at many clinics were required to pay for a substantial part of MMT services. In Haiphong, for example, clients pay 10,000 VND (about $0.50 \mathrm{USD}$ ) daily or nearly 15 USD every month $[8,14]$.

An evaluation of Haiphong's MMT program in 2008 revealed that dropout rates were low, only about $6 \%$ during the first 6 months of treatment [15] and much less than among MMT clients in the nearby countries of China and Malaysia [16-18]. However, later unpublished data from clinics indicated that dropout rates were higher, from 10 to $23 \%$ during the first 2 years, although still less than in other countries. Nevertheless, a more detailed understanding of factors associated with retention would substantially contribute to the development of appropriate interventions to improve the MMT program in Vietnam. Therefore, we performed a longitudinal study of clients in MMT clinics in Haiphong to measure retention rates over a 3 -year period and to identify reasons for dropping out.

\section{Methods}

\section{Study subjects and sampling}

We evaluated patients enrolled from August 2011 to July 2012 in five newly opened MMT clinics in Haiphong and followed them for up to 36 months. The Vietnamese national methadone treatment policy states that clients must obtain methadone at the clinic site daily; those who miss more than five consecutive doses but less than 30 in 1 month are allowed to return for treatment but have to restart methadone at the initiation dose. Those who miss more than 30 consecutive days are considered to have dropped out and are not allowed to re-enroll in a drug substitution program.

We performed two different evaluations. Based on clinic records, we first determined the number and proportion of clients each year who discontinued treatment for more than five consecutive doses and of those who permanently dropped out. Secondly, we identified and attempted to trace those clients who had completed 2 years of treatment but during their third year had either permanently dropped out or had missed more than five consecutive doses. We did not trace clients who dropped out during their first 2 years of MMT, because we were interested in factors associated with longer term retention.

After 2 years of MMT, 819 clients remained in the program. During the subsequent 12 months, 68 clients missed more than five consecutive doses but had returned to treatment, and 115 clients had permanently dropped out; we attempted to locate all 183 of these clients. For each client who had either dropped out or had been non-compliant, and who could be traced and interviewed (case), we identified two clients who remained in treatment throughout their third year of MMT, matching by sex, age, and period of initial enrolment (controls).

Individual interviews of clients who dropped out and who were retained were conducted by research staff at a private location separate from the MMT clinic. The questionnaire included structured items about demographics, use of heroin during the last month of MMT, other drug use, distance from home to the clinic, and whether the client had friends who were using opiates, among other questions. Cases were also asked to respond to close-ended questions about reasons why they had dropped out of treatment. Information on most recent methadone dose, results of hepatitis $\mathrm{C}$ and $\mathrm{B}$ and HIV testing, and anti-retroviral treatment was abstracted from clinic records. 


\section{Analysis}

Data were analyzed in Stata (v. 10.0). The proportion of clients who missed more than five consecutive doses and who permanently dropped out during each 12-month period was calculated. Characteristics of those who dropped out during their third year of MMT and of controls were analyzed using frequency distributions. Factors associated with a combined dropout variable (either missing more than five doses or permanently dropping out) between 24 and 36 months of treatment were determined using univariate logistic regression. Factors associated with the combined dropout variable at $p \leq 0.20$ on univariate analysis were included in a multivariable logistic regression model. Model fitness was assessed by using the linktest and the Hosmer-Lemeshow test.

\section{Ethical approval}

The protocol was approved by the Committee on Human Subjects of the University of California, San Francisco; the Institutional Review Board of the Haiphong University of Medicine and Pharmacy; and the US Centers for Disease Control Global AIDS Program Associate Director of Science. Cases and controls provided written informed consent to be interviewed and to have their medical records abstracted.

\section{Results}

Among 1055 clients initially enrolled, 111 (10.5\%) permanently dropped out and $32(3.0 \%)$ missed greater than five doses during the first year of MMT (Table 1). Among the 944 patients who were on treatment at the start of the second year, 124 (13.1\%) dropped out and 32 (3.4\%) missed more than five doses during the following 12 months; 819 clients were in treatment at 24 months, of whom 115 (14.0\%) dropped out and 68 (8.3\%) missed more than five consecutive doses during the subsequent year. Over the 3-year period, a total of 350 (33.2\%) clients had permanently dropped out. Reasons for dropout that were recorded on clinic records are shown in Table 1. A total of 37 (10.6\%) had died, 84 (24.0\%) had been arrested, 25 (7.1\%) had transferred to another clinic, and reasons were unknown for 138 (39.4\%).

We attempted to locate all 115 persons who had permanently dropped out during their third year of MMT, of whom we were able to locate and interview 28 (24.3\%); we also tried to trace all 68 who had missed more than five consecutive doses during the same period, of whom $53(77.9 \%)$ were traced; therefore, we interviewed 81 cases. We also interviewed 161 matched controls still in treatment. Characteristics of cases and controls are shown in Table 2. Almost all (97.9\%) clients interviewed were male; slightly less than one half were unemployed. Those who dropped out had slightly lower levels of education, with $71.4 \%$ having completed secondary school or less, compared to $50.7 \%$ of those who were retained in treatment; they were also more likely to have children (78.7 versus $58.4 \%$ ). The mean methadone dose of those who permanently dropped out (79.4 $\mathrm{mg} /$ day) and those who missed more than five doses (57.1 mg/day) were lower than among those who continued treatment (111.7 $\mathrm{mg} /$ day $)$.

Characteristics associated with dropping out either permanently or for more than 5 days are shown in Table 3 and include continuing to use heroin (odds ratio $[\mathrm{OR}]=8.92,95 \%$ CI 3.96-20.13, $p<0.001)$ and selfreport of a mental health issue $(\mathrm{OR}=1.9,95 \% \mathrm{CI}$ $1.1-3.29, p=0.021)$. Those who were not married $(\mathrm{OR}=0.49,95 \%$ CI $0.28-0.86, p=0.013)$ were HIV infected $(\mathrm{OR}=0.33,95 \%$ CI $0.33-0.65, p=0.001)$, and those who received $>60 \mathrm{mg} /$ day of methadone were less likely to drop out. Factors independently associated with dropping out were continuing to use heroin during the last month of MMT (adjusted OR $[\mathrm{aOR}]=12.4 ; 95 \% \mathrm{CI} 4.2-36.8, p<0.01)$ and receiving a low dose of methadone $(<60 \mathrm{mg} /$ day $)$.

Table 1 Dropout among patients in methadone treatment during 3 years of following-up in Haiphong, Vietnam (2012-2014)

\begin{tabular}{|c|c|c|c|c|c|c|c|c|c|c|c|c|c|c|}
\hline \multirow[b]{3}{*}{ All } & \multicolumn{4}{|c|}{$\begin{array}{l}0-12 \text { months } \\
(N=1055)\end{array}$} & \multicolumn{4}{|c|}{$\begin{array}{l}13-24 \text { months } \\
(N=944)\end{array}$} & \multicolumn{4}{|c|}{$\begin{array}{l}25-36 \text { months } \\
(N=819)\end{array}$} & \multirow{2}{*}{\multicolumn{2}{|c|}{$\begin{array}{l}\text { Total } \\
\text { dropped } \\
\text { out over } \\
3 \text { years }\end{array}$}} \\
\hline & \multicolumn{2}{|c|}{$\begin{array}{l}\text { Dropped out } \\
N=111 ; n(\%)\end{array}$} & \multicolumn{2}{|c|}{$\begin{array}{l}\text { Missed }>5 \text { doses } \\
N=32 ; n(\%)\end{array}$} & \multicolumn{2}{|c|}{$\begin{array}{l}\text { Dropped out } \\
N=124 ; n(\%)\end{array}$} & \multicolumn{2}{|c|}{$\begin{array}{l}\text { Missed }>5 \text { doses } \\
N=32 ; n(\%)\end{array}$} & \multicolumn{2}{|c|}{$\begin{array}{l}\text { Dropped out } \\
N=115 ; n(\%)\end{array}$} & \multicolumn{2}{|c|}{$\begin{array}{l}\text { Missed }>5 \text { doses } \\
N=68 ; n(\%)\end{array}$} & & \\
\hline & 111 & $(10.5)$ & 32 & (3.0) & 124 & $(13.1)$ & 32 & (3.4) & 115 & $(14.0)$ & 68 & (8.3) & 350 & $(33.2)$ \\
\hline \multicolumn{15}{|l|}{ Reasons for dropout ${ }^{a}$} \\
\hline Death & 21 & $(18.9)$ & 0 & $(0.0)$ & 9 & $(7.3)$ & 0 & $(0.0)$ & 7 & $(6.1)$ & 0 & $(0.0)$ & 37 & (10.6) \\
\hline Arrest & 26 & $(23.4)$ & 0 & $(0.0)$ & 38 & $(30.6)$ & 0 & $(0.0)$ & 20 & $(17.4)$ & 3 & $(4.4)$ & 84 & $(24.0)$ \\
\hline Transfer to another clinic & 11 & $(9.9)$ & 0 & $(0.0)$ & 7 & (5.6) & 0 & $(0.0)$ & 7 & (6.1) & 0 & $(0.0)$ & 25 & $(7.1)$ \\
\hline Other ${ }^{b}$ & 12 & $(10.8)$ & 5 & $(15.6)$ & 11 & $(8.9)$ & 7 & $(21.9)$ & 43 & (37.4) & 50 & $(73.5)$ & 66 & (18.9) \\
\hline Not listed & 41 & (36.9) & 27 & $(84.4)$ & 59 & $(47.6)$ & 25 & $(78.1)$ & 38 & (33.0) & 15 & $(22.1)$ & 138 & (39.4) \\
\hline
\end{tabular}

${ }^{a}$ Based on clinical records

${ }^{\mathrm{b}}$ Family conflicts, side effects, demotivated, and travel 
Table 2 Comparison of those who missed greater than five consecutive doses, who dropped out completely, and who were retained on methadone between 27 and 36 months of treatment in Haiphong (2014)

\begin{tabular}{|c|c|c|c|c|c|c|}
\hline \multirow{3}{*}{$\begin{array}{l}\text { Variable } \\
\text { Demographic characteristics }\end{array}$} & \multicolumn{4}{|c|}{ Cases } & \multirow{2}{*}{\multicolumn{2}{|c|}{$\begin{array}{l}\text { Controls } \\
\text { In treatment } \\
N=161 ; n(\%)\end{array}$}} \\
\hline & \multicolumn{2}{|c|}{$\begin{array}{l}\text { Dropped out } \\
N=28 ; n(\%)\end{array}$} & \multicolumn{2}{|c|}{$\begin{array}{l}\text { Missed }>5 \text { doses } \\
N=53 ; n(\%)\end{array}$} & & \\
\hline & & & & & & \\
\hline \multicolumn{7}{|l|}{ Age, years } \\
\hline $24-30$ & 5 & $(17.9)$ & 6 & $(11.3)$ & 20 & $(12.4)$ \\
\hline $31-40$ & 17 & $(60.7)$ & 27 & $(50.9)$ & 85 & $(52.8)$ \\
\hline $41-50$ & 6 & $(21.4)$ & 14 & $(26.4)$ & 43 & $(26.7)$ \\
\hline $51-59$ & 0 & $(0.0)$ & 6 & $(11.3)$ & 13 & $(8.1)$ \\
\hline Mean, years (SD) & 36.7 & $(5.5)$ & 39.6 & $(7.4)$ & 38.4 & $(7)$ \\
\hline Male & 27 & $(96.4)$ & 52 & $(98.1)$ & 158 & $(98.1)$ \\
\hline \multicolumn{7}{|l|}{ Educational level completed } \\
\hline Primary school & 2 & $(7.1)$ & 3 & $(5.7)$ & 15 & $(9.4)$ \\
\hline Secondary school & 18 & $(64.3)$ & 20 & $(37.7)$ & 66 & $(41.3)$ \\
\hline High school & 6 & $(21.4)$ & 28 & $(52.8)$ & 73 & $(45.6)$ \\
\hline College/university or higher & 2 & $(7.1)$ & 2 & (3.8) & 6 & $(3.8)$ \\
\hline \multicolumn{7}{|l|}{ Marital status } \\
\hline Single & 7 & $(25)$ & 10 & $(18.9)$ & 56 & $(34.8)$ \\
\hline Married & 17 & $(60.7)$ & 37 & $(69.8)$ & 80 & $(49.7)$ \\
\hline Separated/divorced/widowed & 4 & $(14.3)$ & 6 & $(11.3)$ & 25 & $(15.5)$ \\
\hline Live with family & 25 & $(89.3)$ & 51 & $(96.2)$ & 153 & (95) \\
\hline Have children & 6 & $(21.4)$ & 12 & $(22.6)$ & 67 & $(41.6)$ \\
\hline Unemployed & 12 & $(42.9)$ & 23 & $(43.4)$ & 62 & $(38.5)$ \\
\hline \multicolumn{7}{|l|}{ Methadone treatment } \\
\hline Distance from house to the MMT clinic, mean (SD), km & 3.9 & $(1.9)$ & 5.6 & $(7.4)$ & 3.9 & $(3.1)$ \\
\hline \multicolumn{7}{|l|}{ Most recent methadone maintenance dose, mg/day } \\
\hline $5-59$ & 9 & $(33.3)$ & 34 & $(64.2)$ & 43 & $(26.7)$ \\
\hline $60-119$ & 11 & $(40.7)$ & 14 & $(26.4)$ & 62 & $(38.5)$ \\
\hline $120-380$ & 7 & $(25.9)$ & 5 & $(9.4)$ & 56 & $(34.8)$ \\
\hline Mean(SD) & 79.4 & $(44)$ & 57.1 & $(43.5)$ & 111.7 & $(78.8)$ \\
\hline \multicolumn{7}{|l|}{ Drug and alcohol use $\mathrm{a}^{\mathrm{a}}$} \\
\hline Used heroin in the last month of MMT & 11 & $(39.3)$ & 17 & $(32.1)$ & 9 & $(5.6)$ \\
\hline Used other drugs in the last month of MMT & 0 & $(00)$ & 3 & $(5.7)$ & 13 & $(8.1)$ \\
\hline Drank alcohol during the last 3 months of MMT & 21 & $(75)$ & 34 & $(64.2)$ & 101 & $(62.7)$ \\
\hline Medical history & & $(17.9)$ & & & & $(36.6)$ \\
\hline HIV sero-positive & 5 & & 8 & $(15.1)$ & 59 & \\
\hline HbsAg positive & 4 & $(14.3)$ & 5 & $(9.4)$ & 14 & $(8.7)$ \\
\hline HCV positive & 8 & $(28.6)$ & 25 & $(47.2)$ & 73 & $(45.3)$ \\
\hline Self-reported mental health problems in the last 3 months ${ }^{b}$ & 13 & $(46.4)$ & 38 & $(71.7)$ & 76 & $(47.2)$ \\
\hline Have current friends who use drugs & 13 & $(46.4)$ & 28 & $(52.8)$ & 97 & $(60.2)$ \\
\hline
\end{tabular}

aprior to dropping out

${ }^{b}$ Symptoms of anxiety, depression, and suicidal ideation or attempt

Among the 81 clients who dropped out and were interviewed, the most common reason given for discontinuing treatment was lack of continued dependence on heroin (22.2\%) (Table 4). Many also felt that going to the clinic on a daily basis interfered with their work (12.0\%), $16.0 \%$ had a health problem that prevented regular 
Table 3 Factors associated with methadone non-compliance (either dropped out or missed $<5$ days) during 27-36 months of treatment in Haiphong (2014); $N=242$

\begin{tabular}{|c|c|c|c|c|c|c|}
\hline \multirow{2}{*}{$\begin{array}{l}\text { Variable } \\
\text { Age, years }\end{array}$} & \multicolumn{2}{|c|}{$\begin{array}{l}\text { Crude OR } \\
(95 \% \mathrm{Cl})\end{array}$} & \multirow[t]{2}{*}{$p$} & \multicolumn{2}{|c|}{$\begin{array}{l}\text { Adjusted OR } \\
(95 \% \mathrm{Cl})\end{array}$} & \multirow[t]{2}{*}{$p$} \\
\hline & & & & & & \\
\hline $24-40$ & Ref & & & & & \\
\hline $41-59$ & 0.89 & $(0.50-0.56)$ & 0.677 & & & \\
\hline \multicolumn{7}{|l|}{ Gender } \\
\hline Female & Ref. & & & & & \\
\hline Male & 0.75 & $(0.12-0.58)$ & 0.755 & & & \\
\hline \multicolumn{7}{|l|}{ Educational level completed } \\
\hline Secondary school and lower & Ref. & & & & & \\
\hline High school and higher & 0.91 & $(0.53-0.55)$ & 0.718 & & & \\
\hline \multicolumn{7}{|l|}{ Marital status } \\
\hline Married & Ref. & & & Ref & & \\
\hline Single/widowed/divorced/separated & 0.49 & $(0.28-0.86)$ & 0.013 & 0.67 & $(0.24-1.86)$ & 0.440 \\
\hline \multicolumn{7}{|l|}{ Have children } \\
\hline No & Ref. & & & Ref & & \\
\hline Yes & 2.50 & $(1.36-0.59)$ & 0.003 & 2.84 & $(0.88-9.14)$ & 0.081 \\
\hline Distance from house to the MMT clinic, mean (SD), km & 1.06 & $(0.99-0.13)$ & 0.054 & 1.07 & $(0.96-1.20)$ & 0.228 \\
\hline \multicolumn{7}{|l|}{ Most recent methadone dose (mg/day) } \\
\hline $5-59$ & Ref. & & & Ref & & \\
\hline $60-119$ & 0.40 & $(0.22-0.76)$ & 0.005 & 0.40 & $(0.17-0.94)$ & 0.036 \\
\hline 120-380 & 0.36 & $(0.10-0.46)$ & $<0.001$ & 0.28 & $(0.09-0.86)$ & 0.026 \\
\hline \multicolumn{7}{|l|}{ Number of doses of methadone missed, last 3 months } \\
\hline No missed doses & Ref. & & & Ref & & \\
\hline $1-3$ doses & 3.61 & $(1.66-7.87)$ & 0.001 & 2.21 & $(0.86-5.66)$ & 0.098 \\
\hline$>3$ doses & 24.4 & $(10.83-4.98)$ & $<0.001$ & 18.48 & $(7.25-47.09)$ & $<0.001$ \\
\hline \multicolumn{7}{|l|}{ Used heroin during last month of MMT } \\
\hline No & Ref. & & & Ref & & \\
\hline Yes & 8.92 & $(3.96-20.13)$ & $<0.001$ & 12.40 & $(4.19-36.75)$ & $<0.001$ \\
\hline \multicolumn{7}{|l|}{ Have current friends who use drugs } \\
\hline No & Ref. & & & Ref & & \\
\hline Yes & 0.68 & $(0.39-1.16)$ & 0.154 & 0.62 & $(0.29-1.31)$ & 0.207 \\
\hline \multicolumn{7}{|l|}{ HIV status } \\
\hline Negative & Ref. & & & Ref & & \\
\hline Positive & 0.33 & $(0.17-0.65)$ & 0.001 & 1.06 & $(0.39-2.93)$ & 0.907 \\
\hline \multicolumn{7}{|l|}{ Self-reported mental health problems, last 3 months } \\
\hline No & Ref. & & & Ref & & \\
\hline Yes & 1.90 & $(1.10-3.29)$ & 0.021 & 0.99 & $(0.45-2.17)$ & 0.983 \\
\hline
\end{tabular}

attendance, and $14.8 \%$ stated that they were unable to afford the cost of treatment.

\section{Discussion}

This is one of the few studies to systematically evaluate long-term dropout of clients in methadone treatment in Vietnam. Two thirds of all patients who initiated treatment remained in the program after 3 years. Since the rollout of MMT in Vietnam, only a few other studies have evaluated dropout rates, but they have been over short periods of follow-up [8, 19]. A 2009 study of MMT clinics in Haiphong and Ho Chi Minh City found $10 \%$ of clients failed to return during the first 9 months, similar to the $11 \%$ dropout we found during the first 
Table 4 Reasons for quitting methadone maintenance treatment, based on individual interviews ${ }^{* *}$

\begin{tabular}{|c|c|c|c|c|c|c|}
\hline \multirow{2}{*}{$\begin{array}{l}\text { Reasons } \\
\text { I am not dependent on heroin anymore }\end{array}$} & \multicolumn{2}{|c|}{$\begin{array}{l}\text { Dropped out } \\
N=28 n(\%)\end{array}$} & \multicolumn{2}{|c|}{$\begin{array}{l}\text { Missed }>5 \text { doses } \\
N=53 N(\%)\end{array}$} & \multicolumn{2}{|c|}{$\begin{array}{l}\text { All } \\
N=81 N(\%)\end{array}$} \\
\hline & 12 & $(42.9)$ & 7 & $(13.2)$ & 19 & $(23.5)$ \\
\hline Intentionally want to quit dependence on methadone & 0 & & 4 & $(7.5)$ & 4 & $(4.9)$ \\
\hline Cannot tolerate side effects of methadone & 1 & (3.6) & 1 & $(1.9)$ & 2 & $(2.5)$ \\
\hline Demotivated, methadone treatment is too long & 1 & $(3.6)$ & 1 & (1.9) & 2 & $(2.5)$ \\
\hline Time required for MMT conflicts with work & 4 & $(14.3)$ & 12 & (22.6) & 17 & $(21.0)$ \\
\hline Cannot afford methadone fee & 6 & (21.4) & 6 & $(11.3)$ & 12 & $(14.8)$ \\
\hline Have a health problem and cannot get to clinic & 1 & (3.6) & 12 & (22.6) & 13 & $(16.0)$ \\
\hline Gave birth/unavailable for methadone & 0 & & 1 & (1.9) & 1 & $(1.2)$ \\
\hline Family conflict & 1 & (3.6) & 3 & $(5.7)$ & 4 & $(4.9)$ \\
\hline Moved away & 1 & (3.6) & 0 & & 1 & $(1.2)$ \\
\hline Extended travel away from city & 0 & & 3 & & 3 & \\
\hline Arrested & 0 & & 3 & & 3 & \\
\hline No reason given & 1 & (3.6) & 0 & & 1 & $(1.2)$ \\
\hline
\end{tabular}

"**Based on interviews with 81 persons who dropped out between 25 and 36 months

year [5, 19]; another study of six pilot MMT programs found a 2-year dropout of $22 \%$ [5]. Most studies from other countries in the region also report retention during the first year, except for an evaluation conducted in China that followed clients for up to 6 years; the proportion of clients who remained in treatment after 36 months was $66 \%$, similar to our study [17, 20].

Our 1-year dropout rate was considerably lower than that reported from other countries in the region and from some western countries [16, 18, 21, 22]. In Malaysia, $38 \%$ of clients dropped out by 12 months [16], and in China, $73 \%$ failed to be retained after 1 year [18, 23]. Others studies from the west and Israel found 1-year dropout rates to range from 27 to $40 \%$ [22, 24, 25]. In contrast, a study from Germany found 6-year dropout rates to be very low, less than $25 \%$, but this could be attributed to the fact that buprenorphine as well as methadone were available and that most clients received treatment from private physicians' offices [26]. Retention of clients in methadone programs in Vietnam may be higher than in other countries because of the careful vetting of Vietnamese drug users before they are allowed to access treatment $[4,8]$. Those permitted to enter methadone programs must demonstrate stable family or other support systems that a priori may ensure their adherence. Potential clients must also have identity cards and be officially certified as drug users with the local authorities. These policies deter less stable individuals from seeking treatment, including internal migrants, those who are indigent, and those involved in any type of criminal activity. The selection process for MMT in Vietnam has been slightly relaxed since mid-2015; prospective clients are now required to present only a household registration or an identification card but still need to pay some of the cost of methadone treatment. In Haiphong, MMT clinics have recently removed the requirement for identity cards, and this has helped to increase the number of PWID who are receiving drug substitution.

We found that the factors most strongly associated with MMT dropout were continued use of heroin while taking methadone and being administered a methadone dose of less than $60 \mathrm{mg} /$ day. Numerous studies have demonstrated relationships between both continued drug use and inadequate methadone dosing and poor retention. Higher doses of methadone have been shown to be better at preventing PWID from using illicit opiates while on treatment and improving adherence to treatment [17, 20, 27-34]. The US National Institutes of Health recommends $60 \mathrm{mg} /$ day as the lowest effective dose for opiate substitution [35]. Given that one third of patients who dropped out in our study were on less than this amount, Vietnam's guidelines for methadone dosing should be re-evaluated.

In our study, the primary reasons for non-compliance given by those who had dropped out included conflict with work and the requirement to attend clinic on a daily basis. In many MMT programs in other countries, methadone can be provided to clients for days at a time or even weeks if they are stable. In Vietnam, however, clients must go to the clinic 7 days a week to receive treatment or even twice a day if dosing is divided to reduce drug interactions. These requirements can be burdensome, particularly because clients can only access the MMT clinic in the same district where they have permanent residence. To address these issues, the Vietnam MMT program is considering changing its guidelines to 
make buprenorphine available which could allow clients to come for refills every several weeks. [36]. In addition, Vietnam may also start using electronic patient cards or fingerprint scanning to help track patients between clinics and thereby allow them to receive methadone at a variety of sites. Other means of improving adherence could involve co-location of MMT and other health services, including HIV treatment clinics [14, 37]. Better integration of health services in Vietnam has been found to improve quality of life, satisfaction with services, and improved retention on ART among those who were HIV infected [37, 38].

Many participants in our study who dropped out also mentioned that the \$15 monthly co-payment was excessively burdensome. Overall, Vietnam is experiencing a national shortfall in funding for HIV-related services, including those for PWID [14, 39]. To help off-set deficits, the provinces, which are responsible for running the MMT clinics and paying for staff, can levy a fee on clients; the methadone itself is provided by the national government. Part of the rationale for the fee was based on estimating that $\$ 15$ was less than $5 \%$ of what most PWID spent on illicit opiates per month. In addition, an evaluation during the initial rollout of MMT in Haiphong found that among clients surveyed, \$15 per month was considered acceptable [14]. However, these costs need to be included in out-of-pocket health care costs which may also need to be paid by PWID and their families, given the considerable level of co-morbidity among drug users [40]. The greater integration of MMT with other health services, as well as a sliding scale for co-payment, have been suggested as a way to address the economic burden of treatment [40].

Our study had several limitations. We found it difficult to trace clients who had permanently dropped out and were only able to interview one quarter of them, resulting in a loss of representativeness. The majority of clients whom we traced were those who had missed more than five consecutive doses and had re-entered the program; these persons may be fundamentally different from those who have permanently discontinued treatment. Clients were asked structured questions about reasons for dropping out which did not allow us to explore these or other issues that may have been of equal or greater importance.

Nevertheless, we demonstrated that 3-year retention rates were high among the MMT clients in Haiphong and were able to identify several factors that could have an important impact on the long-term efficacy of methadone treatment. Programs should consider sliding fees for co-payment, so that clients should not be expected to subsidize the cost of running the clinics, preventing them from being able to continue treatment. Making methadone available to stable clients for longer periods of time would facilitate job retention and travel. The use of electronic record systems, linking of facilities, and unique identification of clients would allow those in treatment to receive care throughout the province or the country, further enabling retention. These changes, as well as removing the barriers to being eligible to receive methadone in the first place, could go a long way in improving the number of PWID who can receive opiate substitution therapy. This would reduce the substantial burden not only of drug use but also of the HIV epidemic in Vietnam.

\section{Conclusion}

By 3 years, one third of patients under methadone treatment had permanently dropped out. Ensuring that methadone dosing is adequate, reconsidering the co-payment fee, and allowing methadone up to several days so clients can maintain their jobs could improve retention. Introducing buprenorphine in the program would be a good alternative to overcome the weak points above of methadone.

\section{Abbreviations}

aOR: Adjusted odds ratio; MMT: Methadone maintenance therapy; OR: Odds ratio; PWID: Persons who inject drugs; USD: US dollars; VND: Vietnam Dong

\begin{abstract}
Acknowledgements
The authors gratefully thank the Hai Phong Provincial AIDS Centers and the Hai Phong University of Medicine and Pharmacy for their valuable contribution to the data collection.
\end{abstract}

\section{Funding}

This study was supported by the US Centers for Disease Control National Center for HIV/AIDS, Viral Hepatitis, STD, and TB Prevention (5U2GPS001468-05) and the University of California, San Francisco's International Traineeships in AIDS Prevention Studies program (NIMH R25MH064712).

Availability of data and materials

The study team commits to make the data available in hard copy and electronically upon request.

\section{Authors' contributions}

PMK designed the study, supervised the data collection, led the data analysis, and drafted the manuscript. NTT participated in the coordination of the data collection, supervised the data collection, and also participated in the data analysis. DTTM coordinated the research activities between the methadone clinics and participated in the result interpretation. PVT participated in the study design, interpretation of the results, and manuscript writing. PVH participated in study design and manuscript writing. VMT participated in the study design, questionnaire construction, interpretation of the results, and manuscript writing. PVH participated in study design and manuscript writing. $C L$ guided the design of the study and submission of protocols for ethical review, assisted with the data analysis and

interpretation, and chaired the manuscript writing. All authors read and approved the final manuscript.

\section{Ethics approval and consent to participate}

The protocol was approved by the Committee on Human Subjects of the University of California, San Francisco; the Institutional Review Board of the Haiphong University of Medicine and Pharmacy; and the US Centers for Disease Control Global AIDS Program Associate Director of Science. Cases and controls (in the nested case-control study) provided written informed consent to complete a questionnaire and to have their medical records abstracted. 


\section{Consent for publication}

All authors read and approved the final manuscript and consented to publication of this manuscript.

\section{Competing interests}

The authors declare that they have no competing interests.

\section{Publisher's Note}

Springer Nature remains neutral with regard to jurisdictional claims in published maps and institutional affiliations.

\section{Author details}

Haiphong University of Medicine and Pharmacy, 72A, Nguyen Binh Khiem, Ngo Quyen, Haiphong, Vietnam. ${ }^{2}$ The State Council for Professor Title of Vietnam, 1, Dai Co Viet, Bach Khoa, Hai Ba Trung, Hanoi, Vietnam. ${ }^{3}$ Global Health Sciences, University of California, UCSF, 550 16th Street, Third Floor, San Francisco, CA 94158, USA.

\section{Received: 25 April 2017 Accepted: 14 August 2017}

\section{Published online: 30 August 2017}

\section{References}

1. Vietnam Ministry of Health. Report on HIV/AIDS situation and prevention and control HIV/AIDS in 2011. Direction and major tasks in 2012. Hanoi: Vietnam Ministry of Health; 2012. p. 73.

2. Vietnam Ministry of Health. Results from the HIV/STI Integrated Biological and Behavioral Surveillance (IBBS) in Vietnam, Round II, 2009. Hanoi;2009.

3. Vietnam Ministry of Health. Integrated Biological and Behavioral Surveillance (IBBS) in Vietnam—round III 2013. Hanoi;2013.

4. Giang LM, et al. Substance use disorders and HIV in Vietnam since (renovation): an overview. J Food Drug Anal. 2013;21(4):S42-5.

5. Hoang TV, et al. Impact of a methadone maintenance therapy pilot in Vietnam and its role in a scaled-up response. Harm Reduct J. 2015:12:39.

6. Tran BX, et al. Cost-effectiveness of methadone maintenance treatment for HIV-positive drug users in Vietnam. AIDS Care. 2012:24(3):283-90.

7. Tran BX, et al. Changes in drug use are associated with health-related quality of life improvements among methadone maintenance patients with HIV/AIDS. Qual Life Res. 2012;21(4):613-23.

8. Nguyen TT, et al. Methadone maintenance therapy in Vietnam: an overview and scaling-up plan. Adv Prev Med. 2012;2012:732484.

9. Vietnam Ministry of Public Security. Vietnam national report on situation of illicit drugs in 2011 and the first 6 months on 2012. Hanoi;2012.

10. Vietnam Ministry of Health. Pilot project proposal for treatment of opioid dependence by methadone in Hai Phong City and Ho Chi Minh City. Hanoi;2007.

11. Vietnam Ministry of Health. Update of progress in expansion of MMT program until September 2015. Hanoi;2015.

12. Vietnam Ministry of Health. Guidelines on methadone substitution therapy for the treatment of opioid dependence. Hanoi: Medical Publishing House; 2011.

13. Tran, B.X. Modeling the cost-effectiveness of methadone maintenance treatment program on HIV prevention, care and treatment, in 3rd Vietnam National Congress on HIV/AIDS2010: Hanoi, Vietnam.

14. Tran BX. Willingness to pay for methadone maintenance treatment in Vietnamese epicentres of injection-drug-driven HIV infection. Bull World Health Organ. 2013;91(7):475-82.

15. Ministry of Health, Six-month evaluation of methadone maintenance therapy pilot program in Hai Phong and Ho Chi Minh City. 2009.

16. Ramli M, et al. Associated risk factors to non-compliance to methadone maintenance therapy. Med J Malaysia. 2012;67(6):560-4.

17. Wei $X$, et al. A study of 6 -year retention in methadone maintenance treatment among opioid-dependent patients in Xi'an. J Addict Med. 2013; $7(5): 342-8$.

18. Jiang $\mathrm{H}_{\text {, et }}$ al. Factors associated with one year retention to methadone maintenance treatment program among patients with heroin dependence in China. Subst Abuse Treat Prev Policy. 2014:9:11.

19. T. L. Nguyen, D.M.P., T. M. T. Nguyen et al. Summary of the major findings from an evaluation of the pilot methadone maitenance therapy program in Vietnam. J Pract Med Vietnam Minist Health. 2010;3:472-473.
20. Peles E, Schreiber S, Adelson M. Factors predicting retention in treatment: 10-year experience of a methadone maintenance treatment (MMT) clinic in Israel. Drug Alcohol Depend. 2006;82(3):211-7.

21. Lua PL, Talib NS. A 12-month evaluation of health-related quality of life outcomes of methadone maintenance program in a rural Malaysian sample. Subst Use Misuse. 2012:47(10):1100-5.

22. Peles $\mathrm{E}$, et al. One-year and cumulative retention as predictors of success in methadone maintenance treatment: a comparison of two clinics in the United States and Israel. J Addict Dis. 2008:27(4):11-25.

23. Jiang $\mathrm{H}$, et al. Dose, plasma level, and treatment outcome among methadone patients in Shanghai, China. Neurosci Bull. 2016;32(6):538-44.

24. Joe GW, Simpson DD, Broome KM. Retention and patient engagement models for different treatment modalities in DATOS. Drug Alcohol Depend. 1999;57(2):113-25.

25. Carrieri PM, et al. Methadone induction in primary care for opioid dependence: a pragmatic randomized trial (ANRS Methaville). PLoS One. 2014;9(11):e112328.

26. Soyka M, et al. Six-year outcome of opioid maintenance treatment in heroin-dependent patients: results from a naturalistic study in a nationally representative sample. Eur Addict Res. 2017:23(2):97-105.

27. Caplehorn JR, et al. Methadone dose and heroin use during maintenance treatment. Addiction. 1993:88(1):119-24.

28. Faggiano F, et al. Methadone maintenance at different dosages for opioid dependence. Cochrane Database Syst Rev. 2003:3:CD002208.

29. Li L, et al. Multiple substance use among heroin-dependent patients before and during attendance at methadone maintenance treatment program, Yunnan, China. Drug Alcohol Depend. 2011;116(1-3):246-9.

30. Booth RE, Corsi KF, Mikulich-Gilbertson SK. Factors associated with methadone maintenance treatment retention among street-recruited injection drug users. Drug Alcohol Depend. 2004;74(2):177-85.

31. Ward J, Hall W, Mattick RP. Role of maintenance treatment in opioid dependence. Lancet. 1999;353(9148):221-6.

32. Che $Y$, et al. Predictors of early dropout in methadone maintenance treatment program in Yunnan province, China. Drug Alcohol Rev. 2010; 29(3):263-70.

33. Sarasvita $R$, et al. Predictive factors for treatment retention in methadone programs in Indonesia. J Subst Abus Treat. 2012:42(3):239-46.

34. Nguyen $\mathrm{LH}$, et al. Adherence to methadone maintenance treatment and associated factors among patients in Vietnamese mountainside areas. Subst Abuse Treat Prev Policy. 2017;12(1):31.

35. Health, N.I.o., Effective medical treatment of opiate addiction. National Consensus Development Panel on effective medical treatment of opiate addiction. JAMA, 1998. 280(22): p. 1936-1943.

36. Perlman DC, et al. An international perspective on using opioid substitution treatment to improve hepatitis $C$ prevention and care for people who inject drugs: structural barriers and public health potential. Int J Drug Policy. 2015; 26(11):1056-63.

37. Tran BX, et al. Behavioral and quality-of-life outcomes in different service models for methadone maintenance treatment in Vietnam. Harm Reduct J. 2016:13:4

38. Tran BX, et al. Patient satisfaction with methadone maintenance treatment in Vietnam: a comparison of different integrative-service delivery models. PLoS One. 2015;10(11):e0142644

39. Nguyen LH, et al. Quality of life and healthcare service utilization among methadone maintenance patients in a mountainous area of Northern Vietnam. Health Qual Life Outcomes. 2017;15(1):77.

40. Tran BX, et al. Economic vulnerability of methadone maintenance patients: implications for policies on co-payment services. Int J Drug Policy. 2016:31:131-7. 